\title{
DESEMPENHO DO ALGORITMO LMS NA IDENTIFICAÇÃO DE CANAIS VARIANTES NO TEMPO E SEU EMPREGO EM ESQUEMAS DE RECEPÇÃO MLSE-PSP*
}

\author{
Juraci F. Galdino, Ernesto L. Pinto e Marcelo S. de Alencar
}

\begin{abstract}
Resumo - O desempenho do algoritmo Least Mean Square (LMS) na estimação de canais variantes no tempo é avaliado analiticamente. A análise visa a obtenção de curvas de erro médio quadrático (EMQ) em regime permanente adotando um conjunto de hipóteses freqüentemente atendidas em sistemas de comunicações móveis. O canal é modelado por um filtro transversal cujos coeficientes são processos estocásticos estacionários em sentido amplo, com autocorrelações conhecidas. As expressões obtidas para o EMQ são particularizadas para alguns formatos típicos de espalhamento Doppler. Obtém-se também o passo ótimo do algoritmo LMS para alguns dos casos estudados. Diversos resultados analíticos são validados por simulação computacional. O efeito da otimização de passo do LMS sobre $o$ desempenho de um esquema de recepção adaptativo com critério de decisão de máxima verossimilhança aplicado a seqüências de símbolos (Maximum Likelihood Sequence Estimation - MLSE) é também avaliado por simulação.
\end{abstract}

Palavras-chave: Filtragem adaptativa. Desvanecimento variante no tempo e seletivo em freqüência. Erro médio quadrático em regime permanente. LMS. Receptores MLSE adaptativos

Abstract - An analysis of the steady-state mean square er-
ror (MSE) performance of the Least Mean Square (LMS)
algorithm in the identification of time-varying channels is
presented. It is based on a set hypotheses usually adopted
in the mobile communications context. The channel im-
pulse response is modefled as time-varying transversal filter
whose coefficients are wide-sense stationary stochastic pro-
cesses with known power (Doppler) spectra. A generic ex-
pression of the steady state MSE as a function of the LMS
step-size parameter is obtained. Two specific Doppler spec-
trum models are considered for which the optimization of the
LMS step-size parameter in the sense of MSE minimization
is also addressed. Close match between numerical and an-
alytical results is shown in several examples. Besides, the
impact of the LMS step-size parameter optimization on the
performance of an adaptive MLSE (Maximum Likelihood Se-
quence Estimation) receiver is also addressed by Monte Carlo

Juraci Ferreira Galdino e Ernesto Leite Pinto estão vinculados ao Departamento de Engenharia Elétrica do Instituto Militar de Engenharia, Rio de Janeiro, RJ, Brasil. Marcelo Sampaio de Alencar está vinculado ao Departamento de Engenharia Elétrica da Universidade Federal de Campina Grande, Campina Grande, PB, Brasil. E-mails: galdino@epq.ime.eb.br, ernesto@aquarius.ime.eb.br, malencar@dee.ufpb.br. Editor de Área responsável: Abraham Alcaim. Artigo submetido em 20/Ago/2002, revisado em 08/Out/2002, aceito em 05/Fev/2003. simulation.

Keywords: Adaptive filtering. Doubly selective fading. Steady state mean square error. LMS. Adaptive MLSE receivers

\section{INTRODUÇÃO}

O algoritmo de filtragem adaptativa Least Mean Square (LMS) foi proposto há quase meio século e ainda é largamente utilizado em diversas aplicações nas mais variadas áreas do conhecimento humano. Isso se deve, principalmente, à sua baixa complexidade computacional em relação a outros algoritmos, característica de suma importância para certas aplicações, como, por exemplo, sistemas de comunicações móveis. Desde a sua proposição inicial, várias contribuições valiosas ao entendimento desse algoritmo vêm sendo apresentadas em livros, periódicos e congressos. Apesar disso, algumas questões referentes ao seu funcionamento, especialmente as relacionadas com seu emprego em ambientes não-estacionários, estão ainda em aberto.

Até onde vai o conhecimento dos autores, os resultados analíticos para o algoritmo LMS em ambientes nãoestacionários são obtidos impondo condições que são geralmente infringidas em aplicações que envolvem canais de comunicação móvel, particularmente quando caracterizados pelo efeito de desvanecimento variante no tempo e seletivo em frequiência. Em aplicações que se enquadram neste caso, é comum realizar a avaliação de desempenho do algoritmo LMS e a escolha de seu passo via simulação computacional.

É bem conhecido que o passo do algoritmo LMS controla as propriedades de convergência, a estabilidade e o nível de erro médio quadrático (EMQ) em regime permanente do referido algoritmo. Portanto, o uso de um valor adequado para este parâmetro é de vital importância para o seu bom funcionamento.

Diversos artigos recentes exploram de forma analítica a obtenção do EMQ em regime permanente do algoritmo LMS [1-5]. Porém, esses trabalhos modelam a variação temporal dos coeficientes a serem estimados por processos do tipo passeio aleatório ou por processos de Markov de primeira ordem, os quais se distanciam significativamente da modelagem física de canais de comunicações móveis [6].

Neste trabalho três questões importantes são abordadas. Em primeiro lugar, avalia-se em regime permanente o EMQ do algoritmo LMS, quando empregado para identificar

\footnotetext{
${ }^{*}$ Este trabalho foi parcialmente apresentado no IEEE 2002 International Conference on Communications.
} 
canais variantes no tempo. Esta avaliação é realizada de forma analítica, admitindo hipóteses usualmente adotadas em aplicações na área de comunicações móveis. Em segundo lugar, discute-se a obtenção do passo ótimo no sentido de minimizar os valores de EMQ em regime permanente. Para alguns casos aqui tratados, o passo ótimo é obtido analiticamente sem impor aproximaçôes e em outros casos são fornecidas aproximaçôes analíticas para o seu valor. Por fim, avalia-se o desempenho de um esquema particular de recepção MLSE adaptativo que emprega um conjunto de estimadores da resposta ao impulso (RI) do canal baseado no algoritmo LMS com passo otimizado.

As expressões para o EMQ em regime permanente são escritas em termos da função de autocorrelação dos coeficientes da RI do canal e de outros parâmetros típicos do sistema. tais como a variância do ruído e o passo do algoritmo LMS. Essas expressões foram particularizadas para dois modelos de espalhamento Doppler freqüentemente adotados na área de comunicações móveis: o espectro de Jakes e a classe de processos autoregressivos de ordem $M,(\mathrm{AR}(M))$.

$O$ restante do trabalho é organizado da seguinte maneira. Na Seção 2 o modelo adotado para identificação do canal é descrito e as condições impostas para a análise do algoritmo LMS em regime permanente são apresentadas e discutidas. Ainda nessa seção, algumas expressões gerais para o EMQ em regime permanente são deduzidas. Na Seção 3, a expressão de EMQ em regime permanente é particularizada para dois casos de grande interesse na área das comunicações móveis. Essa seção contém ainda uma discussão referente à otimização do valor do passo do algoritmo LMS, tendo como critério a minimização do EMQ na condição de regime permanente. Na Seção 4 são apresentados alguns resultados numéricos e as conclusões do trabalho aparecem na Seção 5 .

A notação adotada neste trabalho é introduzida a seguir. Letras minúsculas em negrito representam vetores ${ }^{1} \mathrm{e}$ as maiúsculas em negrito denotam matrizes. $\mathrm{O}$ símbolo $(\cdot)^{*}$ representa a operação Hermitiana sobre a matriz ou vetor $(\cdot)^{2}$. O símbolo $(\cdot)^{\prime}$ representa a operação transposto do contido entre parênteses. $\operatorname{Tr}(\cdot)$ é usado para simbolizar o traço de $(\cdot)$ e, por fim, $\mathrm{E}[\cdot]$ representa o operador média probabilística.

\section{DESEMPENHO DO LMS NA ESTIMAÇÃO DE CANAIS ESTA- CIONÁRIOS EM SENTIDO AMPLO}

O modelo simplificado do sistema em tempo discreto empregado para identificar os coeficientes da RI do canal é ilustrado na Figura 1. A observação ruidosa no tempo $n \mathrm{e}^{3}$

$$
d(n)=\boldsymbol{w}^{*}(n) \boldsymbol{s}(n)+v(n),
$$

em que $v(n)$ representa o ruído de observação, com variância

\footnotetext{
${ }^{1}$ Os vetores são dispostos em coluna.

2Quando aplicado a escalares essa operação representa o complexo conjugado e para matrizes a sua aplicação resulta na matriz conjugada complexa.

${ }^{3}$ Comete-se aqui um ligeiro abuso de notação, a bem da simplicidade. Na realidade $n$ é adimensional e expressa um particular intervalo de símbolo. $\mathrm{O}$ tempo decorrido do início da transmissão até este intervalo de símbolo é $n T$ segundos.
}

$\sigma_{v}^{2}$ e média nula, $\boldsymbol{s}(n)$ é o vetor de entrada, que é dado por

$$
\boldsymbol{s}(n)=(s(n), s(n-1), \cdots, s(n-L+1))^{\prime}
$$

com $s(m)$ representando o símbolo transmitido no $m$-ésimo intervalo de símbolo, $L$ denotando a quantidade de coeficientes da RI do canal e $\boldsymbol{w}(n)$ um vetor cujos elementos representam os pesos ou coeficientes da RI do canal, que resulta da amostragem da resposta ao impulso conjunta dos filtros de transmissão e recepção e do meio de propagação. Esse vetor é dado por

$$
\boldsymbol{w}(n)=\left(u_{0}(n) \cdot u_{1}^{\prime}(n), \cdots \cdot u_{L-1}(n)\right)^{\prime} .
$$

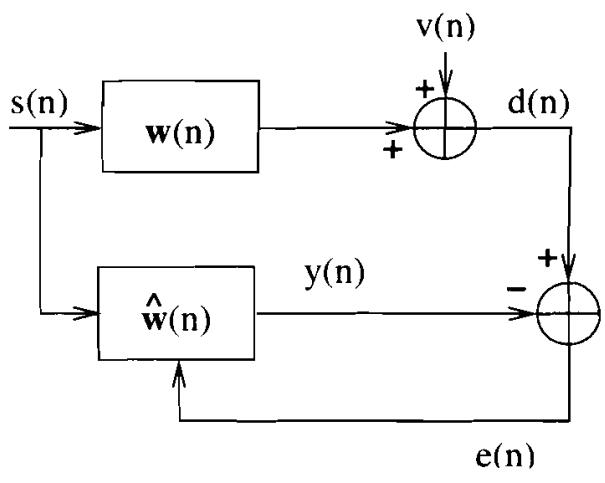

Figura 1. Diagrama de blocos simplificado do sistema em tempo discreto empregado para identificar os coeficientes da RI do canal.

Admite-se que os filtros de transmissão e de recepção são casados e possuem resposta impulsional do tipo raiz quadrada de cosseno levantado [7]. O meio de propagação é modelado por um filtro transversal com $L$ retardos múltiplos do intervalo de símbolo e coeficientes variantes no tempo. A evolução temporal destes coeficientes é modelada por processos estocásticos estacionários em sentido amplo [8] com funções de autocorrelação conhecidas. Considera-se a frequiência de amostragem no receptor igual à taxa de símbolos, de modo que os coeficientes da RI do canal em tempo discreto resultam de fato da amostragem dos respectivos coeficientes da resposta impulsional do meio de propagação.

A estimativa de $\boldsymbol{w}(\cdot)$, que aqui será obtida pelo algoritmo LMS, é denotada por $\hat{\boldsymbol{w}}(\cdot)$. Em particular, para o $(n+1)$ ésimo intervalo de símbolo essa estimativa é expressa por

$$
\hat{\boldsymbol{w}}(n+1)=\hat{\boldsymbol{w}}(n)+\mu \boldsymbol{s}(n) e^{*}(n),
$$

com $\mu$ representando o passo do LMS e e(n) o erro de estimação do sinal recebido, expresso por

$$
e(n)=d(n)-y(n)
$$

sendo

$$
y(n)=\hat{\boldsymbol{w}}^{*}(n) \boldsymbol{s}(n) .
$$

Duas figuras de mérito freqüentemente utilizadas para avaliar o desempenho dos algoritmos de filtragem adaptativa 
são a matriz de covariância do vetor erro $K(n)$ e o EMQ, aqui denotado por $D(n)[1,5]$. Essas figuras de mérito são definidas por:

$$
\boldsymbol{K}(n)=\mathrm{E}\left[\boldsymbol{\epsilon}(n) \boldsymbol{\epsilon}^{*}(n)\right] \quad \text { e } \quad \boldsymbol{D}(n)=\operatorname{Tr}[\boldsymbol{K}(n)],
$$

respectivamente, sendo

$$
\boldsymbol{\epsilon}(n)=\boldsymbol{w}(n)-\hat{\boldsymbol{w}}(n) .
$$

Os elementos do vetor acima, doravante denominado vetor erro, representam os erros produzidos pelo algoritmo LMS na estimação dos coeficientes do canal.

Admite-se que $L$ e as funções de autocorrelação dos coeficientes da RI do canal são conhecidas. Além dessas suposições, são feitas as seguintes:

S1 - O ruído em tempo discreto $\{v(\cdot)\}$ resulta da amostragem de um processo estacionário em sentido amplo que possui média nula e densidade espectral de potência constante dentro da faixa espectral de interesse. Além disso, admite-se que este ruído é estatisticamente independente de $\{s(\cdot)\}$ e de $\{w(\cdot)\}$;

S2 - Os símbolos $\{s(\cdot)\}$ são equiprováveis e independentes, possuem variância $\sigma_{s}^{2}$ e pertencem a uma constelação MPSK simétrica. Desta forma, $\mathrm{E}\left[s(n)^{k} s^{*}(n)^{l}\right]=0$ para quaisquer inteiros $k$ e $l$ com $k+l$ ímpar;

S3 - Em regime permanente $\{\hat{\boldsymbol{w}}(\cdot)\}$ é um processo estocástico estatisticamente independente de $\{s(\cdot)\} .{ }^{4}$

Após substituição das equações (5), (1), (6) e (8) na Equação (4), obtém-se

$$
\hat{\boldsymbol{w}}(n+1)=\hat{\boldsymbol{w}}(n)+\mu \boldsymbol{s}(n) \boldsymbol{s}^{*}(n) \boldsymbol{\epsilon}(n)+\mu \boldsymbol{s}(n) v^{*}(n) .
$$

Usando o fato de que

$$
\boldsymbol{\epsilon}(n+1)=\boldsymbol{w}(n+1)-\hat{\boldsymbol{w}}(n+1),
$$

e a Equação (9), obtém-se

$$
\boldsymbol{\epsilon}(n+1)=\epsilon_{p}(n)-\mu \boldsymbol{s}(n) \boldsymbol{s}^{*}(n) \boldsymbol{\epsilon}(n)-\mu \boldsymbol{s}(n) v^{*}(n)
$$

em que $\epsilon_{p}(n)$, aqui denominado de vetor erro a priori, definido por

$$
\boldsymbol{\epsilon}_{p}(n)=\boldsymbol{w}(n+1)-\hat{\boldsymbol{w}}(n) .
$$

Considerando as suposições e definições apresentadas acima, é mostrado no Apêndice que o EMQ no tempo $n+1$ é dado por

$$
\begin{array}{r}
D(n+1)=\left(1-2 \mu \sigma_{s}^{2}+\mu^{2} L \sigma_{s}^{4}\right) D(n)+\mu^{2} \sigma_{v}^{2} \sigma_{s}^{2} L+ \\
2 \mu \sigma_{s}^{2} \sum_{l=0}^{\infty}\left(1-\mu \sigma_{s}^{2}\right)^{l} \operatorname{Tr}\left[\boldsymbol{R}_{\boldsymbol{w}}(l)-\boldsymbol{R}_{\boldsymbol{w}}(l+1)\right],
\end{array}
$$

sendo

$$
\boldsymbol{R}_{\boldsymbol{w}}(l)=\mathbf{E}\left[\boldsymbol{w}(n) \boldsymbol{w}^{*}(n+l)\right] .
$$

${ }^{4}$ Esta suposição parece razoável se combinada com a suposição $\mathrm{S} 2$, a qual garante que os sinais transmitidos por meio do canal a ser estimado são persistentemente excitantes.
Em regime permanente ${ }^{5}$ tem-se:

$$
D(\mu)=\lim _{n \rightarrow \infty} D(n, \mu)=\lim _{n \rightarrow \infty} D(n+1, \mu) .
$$

Usando esta identidade na Equação (13), obtém-se

$$
\begin{aligned}
D(\mu)= & \frac{1}{\left(2-\mu L \sigma_{s}^{2}\right)}\left\{\mu \sigma_{v}^{2} L+\right. \\
& 2 \sum_{l=0}^{x}\left(1-\mu \sigma_{s}^{2}\right)^{l} \operatorname{Tr}\left[\boldsymbol{R}_{\boldsymbol{w}}(l)\right. \\
& \left.\left.-\boldsymbol{R}_{\boldsymbol{w}}(l+1)\right]\right\} .
\end{aligned}
$$

É razoável admitir que os coeficientes da RI do canal possuem a mesma função de autocorrelação $R(\tau)$, a menos de constantes multiplicativas. Feita esta suposição, tem-se:

$$
\operatorname{Tr}\left[\boldsymbol{R}_{\boldsymbol{w}}(\tau)\right]=\sigma_{u}^{2} R(\tau),
$$

sendo $\sigma_{w}^{2}$ o ganho de potência do canal (para canal normalizado $\sigma_{w}^{2}=1$ ). Daí, o EMQ em regime permanente pode ser escrito como

$$
\begin{aligned}
D(\mu)= & \frac{1}{\left(2-\mu L \sigma_{s}^{2}\right)}\left\{\mu \sigma_{v}^{2} L+\right. \\
& \left.2 \sigma_{w}^{2} \sum_{l=0}^{\infty}\left(1-\mu \sigma_{s}^{2}\right)^{l}[R(l)-R(l+1)]\right\} .
\end{aligned}
$$

É importante observar que os resultados obtidos acima são genéricos, no que diz respeito à função de autocorrelação dos coeficientes do canal. A seguir, o EMQ em regime permanente será particularizado para dois casos de grande interesse na área de comunicações móveis.

\section{DOIS CASOS PARTICULARES}

Esta seção discute dois modelos de espalhamento Doppler que são freqüentemente adotados no âmbito das comunicações móveis. Nominalmente, são investigados o modelo de Jakes [6] e a classe de processos autoregressivos (AR) [1].

A função de autocorrelação referente ao modelo de Jakes é expressa por

$$
R(l)=J_{0}\left(2 \pi f_{D} T l\right)
$$

em que $J_{0}(\cdot)$ é a função de Bessel de primeira classe de ordem zero, $f_{D}$ é o desvio Doppler máximo ou deslocamento Doppler máximo e $T$ é o intervalo de símbolo. Considerando um equipamento de recepção se deslocando a uma velocidade $v$ e que o comprimento de onda da freqüência portadora é $\lambda$, $f_{D}=v / \lambda[6]$.

Usando a Equação (19) na Equação (18), $D(\mu)$ reduz-se a

$$
\begin{aligned}
D(\mu)= & \frac{1}{\left(2-\mu L \sigma_{s}^{2}\right)}\left\{\mu \sigma_{v}^{2} L+\right. \\
& 2 \sigma_{w}^{2} \sum_{l=0}^{\infty}\left(1-\mu \sigma_{s}^{2}\right)^{l}\left[J_{0}\left(2 \pi f_{D} T l\right)-\right. \\
& \left.\left.J_{0}\left(2 \pi f_{D} T(l+1)\right)\right]\right\} .
\end{aligned}
$$

\footnotetext{
${ }^{5}$ Até este ponto a dependência do EMQ com relação a $\mu$ foi omitida para simplificar a notação.
} 
Para um processo AR de ordem $M$, aqui denotado por $\mathrm{AR}(\mathrm{M})$, após o transitório, tem-se

$$
\sum_{k=0}^{M} a_{k}^{*} R(l-k)=0 \quad l>0
$$

$\mathrm{e}$

$$
R(m)=\sum_{k=1}^{M} c_{k} p_{k}^{m}
$$

em que $\left\{a_{h} \cdot k=1,2, \cdots M Y\right\}$ são conhecidos como parâmetros do processo $\mathrm{AR},\left\{c_{k}, k=1,2, \cdots M\right\}$ são constantes e $\left\{p_{k}, k=1,2, \cdots M\right\}$ são raízes da equação [1 $]^{6}$

$$
1+a_{1}^{*} z^{-1}+\cdots a_{1}^{*} z^{-M}=0
$$

Substituindo a Equaçāo (22) na Equação (18) e admitindo que

$$
\left|\left(1-\mu \sigma_{s}^{2}\right) p_{k}\right|<1 \quad \text { para } k=1,2, \cdots, M,
$$

então

$D(\mu)=\frac{1}{\left(2-\mu L \sigma_{s}^{2}\right)}\left\{\mu \sigma_{v}^{2} L+2 \sigma_{w}^{2} \sum_{k=1}^{M} \frac{c_{k}}{1+d_{k} \mu \sigma_{s}^{2}}\right\}$,

na qual

$$
d_{k}=\frac{p_{k}}{1-p_{k}}
$$

É importante considerar que para um processo AR ser assintoticamente estacionário é preciso que $\left|p_{k}\right|<1$ para todo $k$ [1, pp. 97]. Além disso, em aplicações de comunicações móveis o passo do LMS geralmente assume valores pequenos. Considerando esses dois pontos, a suposição expressa na Inequação 24 é razoável, sendo geralmente atendida na prática.

\subsection{DETERMINAÇÃO DO PASSO ÓTIMO}

A obtenção do passo ótimo do algoritmo LMS é o objeto de estudo desta seção. A análise contempla os dois casos particulares tratados na seção precedente e assume a minimização do EMQ em regime permanente como critério de otimização.

No tocante à classe de processos AR, obtém-se explicitamente o passo ótimo para o processo $\operatorname{AR}(1)^{7}$ e se discute a sua obtenção para processos AR de ordem par, sendo dada especial ênfase ao modelo $\operatorname{AR}(2)^{8}$. Com relação ao processo de Jakes, obtém-se uma aproximação analítica do passo ótimo a partir dos resultados obtidos para o processo $\mathrm{AR}(2)$.

\footnotetext{
${ }^{n}$ Um processo $A R(M)$ pode ser gerado aplicando ruído branco na entrada de um filtro digital cuja função de transferência possui apenas polos dados pelas raízes $\left\{p_{k}\right\}$. Por esta razão, doravante estas raizes serão denominadas de polos.

${ }^{7}$ Em outros trabalhos nos quais se discute a obtenção do passo ótimo para ambientes não-estacionários. admite-se geralmente este modelo e. mesmo assim, o passo ótimo é obtido de forma aproximada.

${ }^{8}$ Em receptores adaptativos para canais de comunicações móveis, os modelos AR mais empregados são os de primeira e de segunda ordem [9-12], dai ter sido dado um tratamento especial para esses processos.
}

De acordo com a Equação (20) o EMQ em regime permanente produzido pelo algoritmo LMS na identificação de processos $\mathrm{AR}$ (1) é dado por

$$
D(\mu)=\frac{1}{\left(2-\mu L \sigma_{s}^{2}\right)}\left\{\mu \sigma_{v}^{2} L+\frac{2 \sigma_{w}^{2}}{1+d_{1} \mu \sigma_{s}^{2}}\right\} .
$$

Calculando a derivada parcial da Equação 27 com relação a $\mu$ e igualando o resultado a zero, verifica-se que o passo ótimo pode ser obtido resolvendo-se a seguinte equação

$$
A \mu^{2}+B \mu+C=0
$$

em que:

$$
\begin{aligned}
& A=\sigma_{v}^{2} \sigma_{s}^{4} p_{1} L ; \\
& B=2 p_{1} L \sigma_{s}^{2} \sigma_{w}^{2}\left(1+\sigma_{s}^{2}\right) \quad \mathrm{e} \\
& C=\sigma_{v}^{2} L+\sigma_{s}^{2} \sigma_{w}^{2}\left(L-2 p_{1}\right) .
\end{aligned}
$$

Considerando processos AR(2) com polos complexos conjugados, a Equação (25) pode ser reescrita como segue

$D(\mu)=\frac{1}{\left(2-\mu L \sigma_{s}^{2}\right)}\left\{\mu \sigma_{v}^{2} L+2 \sigma_{w}^{2} \frac{1+\alpha_{1} \mu}{1+\alpha_{2}+\alpha_{3} \mu^{2}}\right\}$,

em que:

$$
\begin{aligned}
\alpha_{1} & =\left(c_{1} d_{1}^{*}+d_{1} c_{1}^{*}\right) \sigma_{s}^{2} \\
\alpha_{2} & =\left(d_{1}+d_{1}^{*}\right) \sigma_{s}^{2} \mathrm{e} \\
\alpha_{3} & =|d|^{2} \sigma_{s}^{4} .
\end{aligned}
$$

Nesse caso, o passo ótimo pode ser obtido resolvendo a equação

$$
A_{1} \mu^{4}+A_{2} \mu^{3}+A_{3} \mu^{2}+A_{4} \mu+A_{5}=0
$$

cujos coeficientes são dados por:

$$
\begin{aligned}
& A_{1}=\sigma_{v}^{2} L \alpha_{3}^{2} \\
& A_{2}=2 \sigma_{v}^{2} L \alpha_{2} \alpha_{3}-4 \alpha_{1} \alpha_{3} L \sigma_{s}^{2} \sigma_{w}^{2} ; \\
& A_{3}=\sigma_{v}^{2} L\left(\alpha_{2}^{2}+2 \alpha_{3}\right)+3 \sigma_{w}^{2}\left(2 \alpha_{1} \alpha_{3}-L \sigma_{s}^{2}\left(\alpha_{1} \alpha_{2}-\alpha_{3}\right)\right) ; \\
& A_{4}=2 \sigma_{v}^{2} L \alpha_{2}+2 \sigma_{w}^{2}\left(2 \alpha_{1} \alpha_{2}-\alpha_{1} L \sigma_{s}^{2}-2 \alpha_{3}+L \sigma_{s}^{2} \alpha_{2}\right) ; \\
& A_{5}=\sigma_{v}^{2} L+\sigma_{w}^{2}\left(2 \alpha_{1}-2 \alpha_{2}+L \sigma_{s}^{2}\right) .
\end{aligned}
$$

Este procedimento pode ser estendido para processos AR de ordem $2 Q$, sendo $Q$ um inteiro maior do que 1 . Nesse caso, o passo ótimo pode ser obtido a partir dos zeros de um polinômio de grau $4 Q$.

É importante mencionar que a expressão de EMQ em regime permanente possui apenas um ponto de mínimo, dentro da faixa de valores que garante a convergência do algoritmo $[1,5]$. Em decorrência disso, as equações (28) e (32) têm apenas uma solução real e positiva, que é o valor do passo ótimo.

É muito difícil obter analiticamente o passo ótimo para o modelo de Jakes a partir da Equação (20). No entanto, o modelo de Jakes pode ser aproximando por um processo AR e o procedimento discutido acima pode ser empregado para obter o passo ótimo do modelo aproximado. Admitindo que existe um bom ajuste entre os modelos aproximado e original, 
pelo menos na faixa de valores próximos da posição do passo ótimo, esse procedimento pode representar uma abordagem interessante para obter uma aproximação analítica para o passo ótimo do modelo de Jakes.

Alguns resultados de trabalhos prévios mostraram que uma boa aproximação analítica do modelo de Jakes, para fins de uso em receptores adaptativos, pode ser obtida com o processo $A R(2)[11$ ]. Isto motivou o emprego deste modelo para determinar a aproximação analítica acima delineada.

Usando. tal como em [1]], a minimização da variância do erro de predição para estabelecer o ajuste entre os modelos envolvidos, o vetor de parâmetros autoregressivos $a$ do modelo aproximado é dado pela seguinte expressão [1, Capítulo 6]

$$
\boldsymbol{a}=\boldsymbol{R}_{J}^{-1} \boldsymbol{r}_{J}(1)
$$

em que $\boldsymbol{R}_{J}$ e $\boldsymbol{r}_{J}(m)$ são especificados pela função de autocorrelação do processo estocástico a ser aproximado . No caso do modelo de Jakes

$$
\boldsymbol{R}_{J}=\left[\begin{array}{cccc}
1 & J_{0}(\tau) & \cdots & J_{0}(\tau(M-1)) \\
J_{0}(\tau) & 1 & \cdots & J_{0}(\tau(M-2)) \\
\vdots & \vdots & \vdots & \vdots \\
J_{0}(\tau(M-1)) & \cdots & J_{0}(\tau) & 1
\end{array}\right]
$$$$
\text { e } \quad r_{J}(m)=\left(J_{0}(\tau(m)) \cdots J_{0}(\tau(m+M))\right)^{\prime} \text {. }
$$

$\operatorname{com} T=2 \pi f_{D} T$

Os polos $\left\{p_{k}\right\}$ podem ser obtidos de $a$ resolvendo a Equação (23) e as constantes da Equação (22), que por conveniência aqui foram agrupadas no vetor $c=\left(c_{1}, \cdots, c_{M}\right)^{\prime}$, podem ser determinadas fazendo

$$
c=\boldsymbol{P}^{-1} \boldsymbol{r}_{J}(0)
$$

na qual

$$
\boldsymbol{P}=\left[\begin{array}{cccc}
1 & 1 & \cdots & 1 \\
p_{1} & p_{2} & \cdots & p_{M} \\
\vdots & \vdots & \vdots & \vdots \\
p_{1}^{M I-1} & p_{2}^{M-1} & \cdots & p_{M}^{M-1}
\end{array}\right]
$$

Usando as equações (33) e (34) os coeficientes do polinômio da Equação (32) ficam completamente especificados e o passo ótimo do modelo aproximado pode ser determinado.

\section{RESULTADOS NUMÉRICOS}

Nesta seção três conjuntos de resultados são apresentados e discutidos. Os dois primeiros procuram validar os resultados analíticos apresentados na seção anterior por meio de simulação computacional, enquanto que o terceiro contempla a avaliação do efeito da otimização do passo do LMS no desempenho de um receptor MLSE adaptativo. Neste caso dois mecanismos de atribuição do passo são investigados: passo otimizado, de acordo com o procedimento proposto na seção anterior, e passo constante. Neste último caso, o valor do passo é determinado a priori no sentido de garantir um compromisso de bom desempenho, considerando uma faixa de valores da razão sinal-ruído (RSR) e diferentes valores do deslocamento Doppler máximo.

Todos os resultados que se seguem foram produzidos considerando modulação QPSK e canal discreto contendo três raios $(L=3)$ com espaçamento entre raios igual ao intervalo de símbolo. Os raios são modelados por processos estacionários e estatisticamente independentes entre si, com o mesmo formato de densidade espectral de potência, o qual é definido pelo modelo de espalhamento Doppler. As simulações contemplam os dois modelos de espalhamento Doppler discutidos na seção anterior.

Foram também realizadas simulações de canais que possuíam RI com outras quantidades de raios, cujos resultados não são apresentados aqui por limitação de espaço. $\mathrm{Na}$ essência, esses resultados estão em conformidade com os apresentados a seguir, principalmente no que se refere ao ajuste entre resultados analíticos e de simulação computacional.

\subsection{EMQ EM REGIME PERMANENTE}

Nas figuras 2, 3, 4 e 5 são apresentadas curvas de EMQ em regime permanente em função do passo do LMS, obtidas analiticamente, e também alguns valores de EMQ (indicados por círculos), que foram obtidos por meio de simulação computacional. Os resultados de cada uma dessas figuras foram obtidos com valores de RSR iguais a 10, 20 e $30 \mathrm{~dB}$.

As figuras 2 e 3 se referem aos processos $A R(1)$ e $A R(2)$, respectivamente. $\mathrm{O}$ parâmetro de regressão do processo AR(1) avaliado é $a_{1}=-0,99$ e para o processo AR(2) os parâmetros são $a_{1}=-1,9999$ e $a_{2}=0,99999$. As figuras 4 e 5 apresentam curvas de EMQ para o processo de Jakes com $f_{D} T=0,001$ e $f_{D} T=0,005$, respectivamente.

Os resultados de simulação computacional foram gerados considerando 500 realizaçôes estatisticamente independentes de todos os processos estocásticos envolvidos na modelagem. Por outro lado, os resultados analíticos para o processo de Jakes foram obtidos usando 300 termos no cálculo do somatório da Equação (20).

Pode-se observar nessas quatro figuras um bom ajuste entre os resultados analíticos e os obtidos por simulação computacional, indicando a validade das análises desenvolvidas e a pertinência das suposições adotadas.

\subsection{PASSO ÓTIMO}

Nesta sub-seção são apresentados resultados numéricos relacionados com a questão da otimização do passo do LMS, no sentido de minimizar o EMQ em regime permanente. Os resultados da Figura 6 foram obtidos considerando o processo $\mathrm{AR}(2)$, e os das figuras 7 e 8 foram gerados para o processo de Jakes com $f_{D} T$ igual a 0,001 e 0.01 , respectivamente.

É importante lembrar que o processo $\mathrm{AR}(2)$ investigado possui polos complexos conjugados, portanto os valores destacados nas curvas da Figura 6 representam valores mínimos de erro médio quadrático na condição de regime estacionário, obtidos resolvendo-se a Equação (32) .

Por outro lado, no caso do modelo de Jakes, os valores de EMQ destacados nas figuras 7 e 8 foram obtidos para os passos estabelecidos de acordo com o procedimento de 


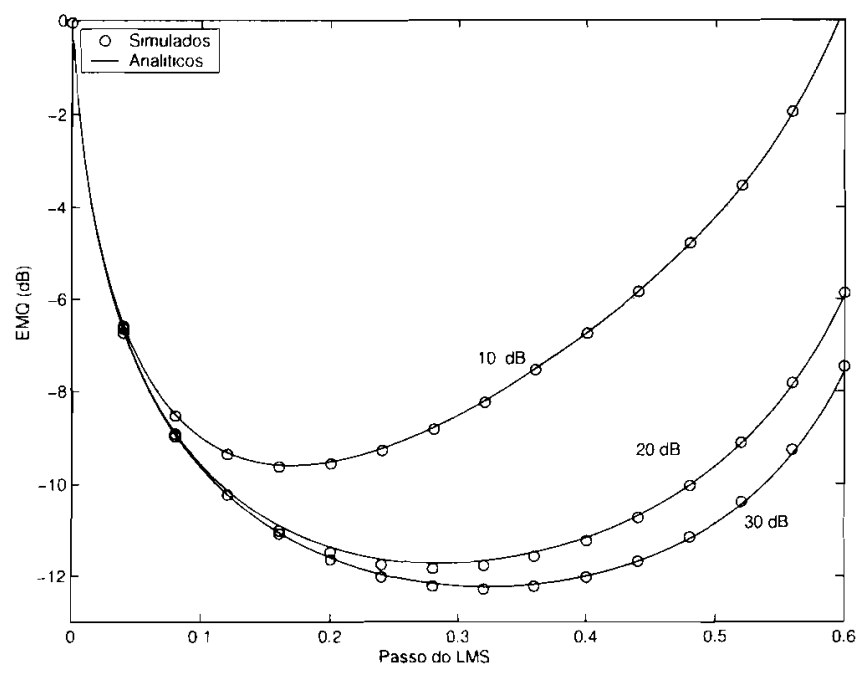

Figura 2. EMQ em regime permanente em função do valor do passo do algoritmo LMS para o processo AR(1). São mostrados resultados analíticos e de simulação para RSR de 10,20 e $30 \mathrm{~dB}$.

aproximação analítica proposto. Ou seja, o modelo de Jakes foi ajustado por um processo $\mathrm{AR}(2)$ com polos complexos conjugados no sentido de minimizar a variância do erro de predição e em seguida o passo ótimo para o modelo aproximado foi determinado. Os resultados numéricos apresentados nas figuras 7 e 8 indicam que o procedimento proposto fornece uma aproximação muito boa para os valores de passo ótimo.

Vale lembrar que o valor do passo exerce forte influência no desempenho do algoritmo LMS. Para se ter uma medida desta influência em termos do EMQ em regime permanente, considere-se o caso em que $f_{D} T=0,001$ e RSR $=20 \mathrm{~dB}$, no qual o valor do passo ótimo é 0,125 (Figura 4). Se este valor de passo for utilizado em um cenário com $f_{D} T=0,01$, ocorrerá uma degradação em torno de $6 \mathrm{~dB}$ relativa ao nível de EMQ que seria atingido caso fosse adotado o valor ótimo do passo (Figura 5). Comportamentos similares podem ser verificados para outras situações.

É importante notar que uma estimativa de $f_{D}$ pode ser obtida a partir de uma estimativa da velocidade do equipamento de recepção, na situação usual em que o transmissor está fixo. Admitindo-se que o efeito Doppler do canal é bem aproximado pelo espectro de Jakes e que também se dispõe de uma estimativa da variância do ruído, o procedimento proposto pode ser usado para estimar e acompanhar o valor do passo ótimo em tempo real. Neste contexto é importante considerar que os receptores de diversas aplicações atuais e futuras na área de comunicações móveis dispõem, ou prevêem a disponibilização, de medidas de velocidade em tempo real, de modo que não haveria necessidade de processamento adicional para obtê-las.

Explicitando a Equação (33) para uma matriz de autocorrelação de tamanho dois, pode-se verificar que os parâmetros regressivos podem ser determinados com apenas três somas e quatro multiplicações reais. Os coeficientes da Equação (34) podem ser determinados com complexidade similar. Diante disso, vê-se que a complexidade computa-

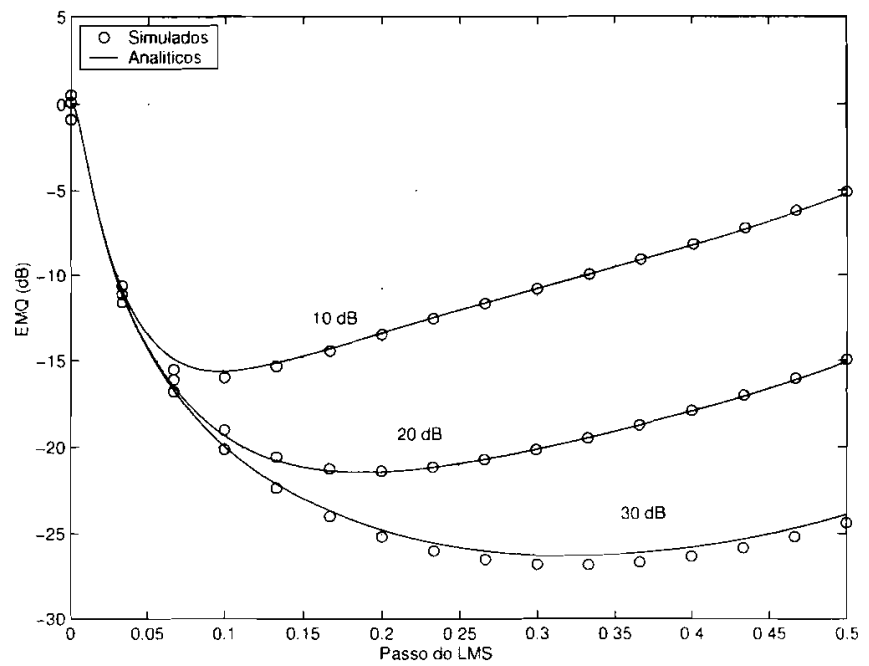

Figura 3. EMQ em regime permanente em função do valor do passo do algoritmo LMS para o processo AR(2). São mostrados resultados analíticos e de simulação para RSR de 10,20 e $30 \mathrm{~dB}$.

cional do procedimento proposto é dominada pelas complexidades de determinação dos zeros dos polinômios de segundo e quarto graus que são apresentados nas equações (23) e (32). Vários algoritmos eficientes para obter as raízes de um polinômio são descritos na literatura técnica [13].

É importante notar que o procedimento proposto para determinação do passo não é recursivo. No entanto, como nas aplicações usuais o parâmetro $f_{D}$ permanece praticamente constante no intervalo de tempo referente ao recebimento de um bloco de símbolos, a determinação do passo só seria necessária no início de cada bloco.

\subsection{APLICAÇÃO A UM RECEPTOR ADAPTA- TIVO MLSE-PSP}

Nesta seção avalia-se o efeito do ajuste do passo sobre o desempenho de um esquema de recepção adaptativo baseado no emprego do algoritmo LMS para estimação do canal. Trata-se especificamente de um receptor MLSE [7, 14]) que emprega o princípio do percurso sobrevivente (Per Survivor Processing - PSP) [11, 15-17]. Este esquema de recepção será aqui denominado MLSE-PSP.

A estrutura básica de um receptor MLSE-PSP é mostrado no diagrama de blocos da Figura 9. Ele usa um conjunto de filtros adaptativos que obtém estimativas de canal condicionadas a determinadas seqüências, denominadas seqüências sobreviventes, que são fornecidas pelo algoritmo de busca. $O$ esquema de recepção MLSE-PSP avaliado neste trabalho emprega o algoritmo de Viterbi $[18][7,14]$ para obter as seqüências sobreviventes e um conjunto de algoritmos LMS para obter estimativas da RI do canal condicionadas às seqüências sobreviventes.

Os receptores MLSE-PSP têm recebido grande atenção no contexto das comunicações móveis, caracterizadas pelo efeito de desvanecimento seletivo em frequiência e variante no tempo, face ao melhor desempenho propiciado em relação à esquemas convencionais, os quais adotam apenas um algo- 


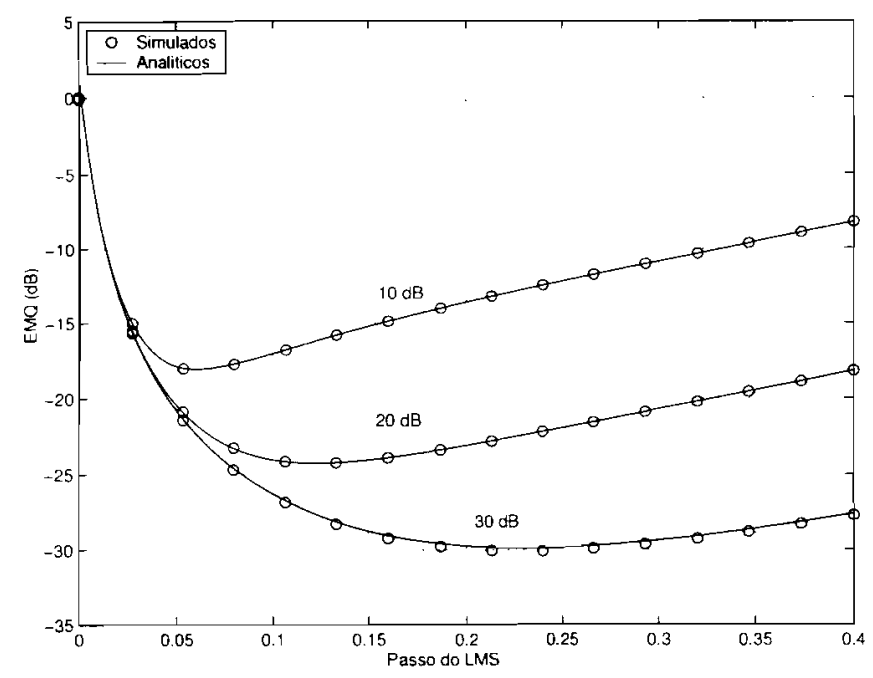

Figura 4. EMQ em regime permanente em função do valor do passo do algoritmo LMS para o processo de Jakes com $f_{D} T=0.001$. São mostrados resultados analíticos e de simulação para RSR de 10, 20 e $30 \mathrm{~dB}$.

ritmo de filtragem adaptativa [7].

O melhor desempenho dos esquemas MLSE-PSP devese a duas razões principais [19]. Em primeiro lugar, não existe retardo na determinação das seqüências sobreviventes, o que é um sério inconveniente para os receptores MLSE convencionais [7]. Em segundo lugar, o esquema de recepção MLSE-PSP utiliza várias seqüências de símbolos para obter a identificação da RI do canal, enquanto que o procedimento convencional emprega apenas uma. Dessa forma, o primeiro esquema produz uma aproximação mais precisa do critério de máxima verossimilhança conjunto (estimação conjunta dos símbolos transmitidos e da RI do canal).

Como nas simulações anteriores, o cenário de comunicação no qual é avaliado o desempenho do referido esquema de recepção emprega canais que possuem perfi] de intensidade de multipercurso discreto contendo três raios espaçados a intervalos de símbolos, porém, neste caso, apenas o espectro de Jakes é utilizado para modelar o espalhamento Doppler. Além disso, o produto $f_{D} T$ é modelado por uma variável aleatória uniforme no intervalo $[0,0020,007]$.

Nas simulações realizadas, são transmitidos blocos de oitenta e oito símbolos QPSK, sendo que os primeiros vinte e quatro símbolos são utilizados como sequiência de treinamento. Assim sendo, o sistema proposto opera com uma vazão de informação aproximadamente igual a $72,3 \%$. O uso da baixa vazão se justifica em razão dos elevados valores de efeito Doppler considerados nas simulações.

No início de cada bloco, o valor de $f_{D}$ é sorteado e mantido constante durante a transmissão de todo o bloco. Este modelo é bastante razoável, pois o deslocamento Doppler máximo fica determinado pela velocidade do receptor, que é aleatória e permanece praticamente inalterada no intervalo de tempo correspondente à transmissão de um bloco de símbolos.

Considerou-se a transmissão de 10.000 blocos e valores de RSR na faixa de 10 até $40 \mathrm{~dB}$, com incrementos de $2 \mathrm{~dB}$. Esses resultados são apresentados nas figuras $10 \mathrm{e} 11$.

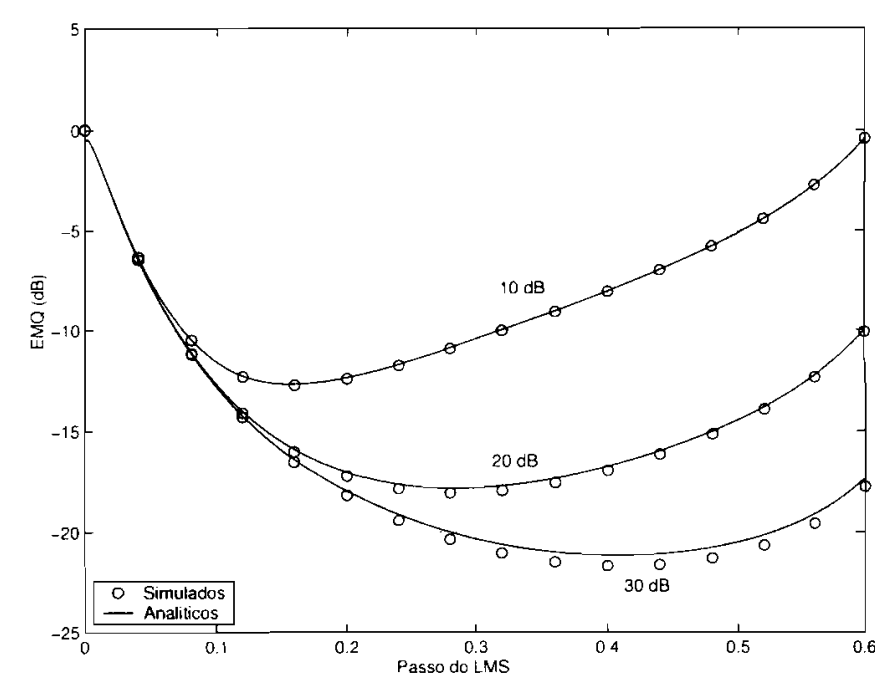

Figura 5. EMQ em regime permanente em função do valor do passo do algoritmo LMS para o processo de Jakes com $f_{D} T=0,005$. São mostrados resultados analíticos e de simulação para RSR de 10,20 e $30 \mathrm{~dB}$.

Na implementação do algoritmo LMS duas formas de atribuição de seu passo foram testadas. Em primeiro lugar, considerando que a velocidade do equipamento de rec:apção e a variância do ruído de observação são conhecidas, onteve-se uma aproximação analítica do passo ótimo para cada bloco de informação transmitido, usando-se o procedimento descrito na Seção 3. Em segundo lugar usou-se o procedimento convencional de fixar o passo do LMS a priori, com base numa solução de compromisso sobre os cenários de transmissão em que será empregado. Este valor de passo fixo foi determinado por simulação, a partir do levantamento prévio de curvas de EMQ em regime permanente para toda a faixa de valores de RSR e para os valores do parâmetro $f_{D} T$ considerados. Nestas condições, o valor 0,2 foi obtido como melhor solução de compromisso.

Na Figura 10 são mostradas as curvas de aprendizagem do algoritmo LMS para os dois esquemas investigados, considerando valores de RSR iguais a 20 e $30 \mathrm{~dB}$. Verifica-se uma rápida convergência do algoritmo, sendo atingido o valor mínimo de EMQ ainda dentro do período de treinamento (24 símbolos). Durante a fase de estimação dos símbolos transmitidos há uma tendência de perda de acompanhamento, face a rápida evolução temporal do canal e os eventuais erros de detecção que prejudicam a atualização da estimativa da RI do canal.

Apesar da perda de acompanhamento, as curvas de aprendizagem obtidas utilizando o procedimento proposto na Seção 3 para otimização do passo são bem melhores do que as curvas de aprendizagem que foram obtidas com a forma convencional de atribuição do passo do algoritmo LMS. Esse melhor comportamento nas curvas de aprendizagem produziu, como pode ser observado na Figura 11, reduções significativas na taxa de erro de bit do receptor.

Com relação à Figura 11, cabe notar que, de maneira geral, o desempenho de esquemas de recepção adaptativos que operam em canais com memória são severamente degradados em 


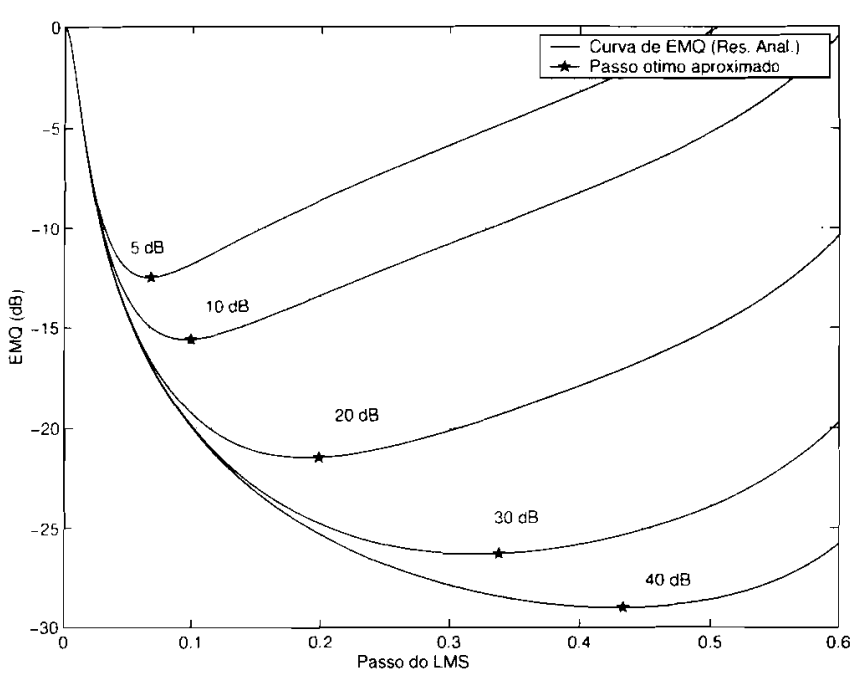

Figura 6. Curvas de EMQ em regime permanente obtidas analiticamente para o processo $\operatorname{AR}(2)$. Em destaque os valores de EMQ para o passo ótimo.

baixa RSR. Isso se deve principalmente ao efeito provocado pelas detecções erradas que prejudicam a atualização da(s) estimativa(s) da RI do canal ou de parâmetros a ela associados, o que, por seu turno, compromete as detecções subseqüentes. Esse círculo vicioso pode levar à perda definitiva do acompanhamento do canal. Para valores elevados da RSR, os erros ocorrem em menor quantidade e o algoritmo adaptativo, no caso em questão o LMS, pode tolerá-los sem desencadear a perda de acompanhamento do canal.

Além disso, é válido ainda observar que a otimização do passo foi realizada considerando a transmissão de símbolos conhecidos, condição que se dá de fato apenas no período de treinamento e pode até ser bem aproximada quando o receptor opera com RSR elevada, mas certamente não se verifica caso a RSR assuma valores baixos.

Esses dois aspectos podem justificar a obtenção de características de desempenho similares nas baixas RSR para as duas estratégias de escolha do passo do LMS (veja figuras 10 e 11), bem como a boa vantagem de desempenho obtida com o procedimento de otimização do passo proposto, para valores de RSR acima de $16 \mathrm{~dB}$.

É importante mencionar que os atuais sistemas de comunicação móveis são em geral projetados para operar em níveis elevados de RSR, situação na qual o procedimento aqui proposto permite melhorar significativamente o desempenho do algoritmo LMS e, por conseguinte, o do esquema de recepção.

\section{CONCLUSÃO}

$O$ desempenho do algoritmo de filtragem adaptativa LMS foi avaliado no contexto da identificação de canais variantes no tempo. Ao contrário de outras abordagens analíticas [1-4], que geralmente lidam com processos do tipo passeio aleatório ou de Markov de primeira ordem para caracterizar a dinâmica de evolução temporal dos coeficientes a serem estimados, a formulação aqui adotada assume que tais coefi-

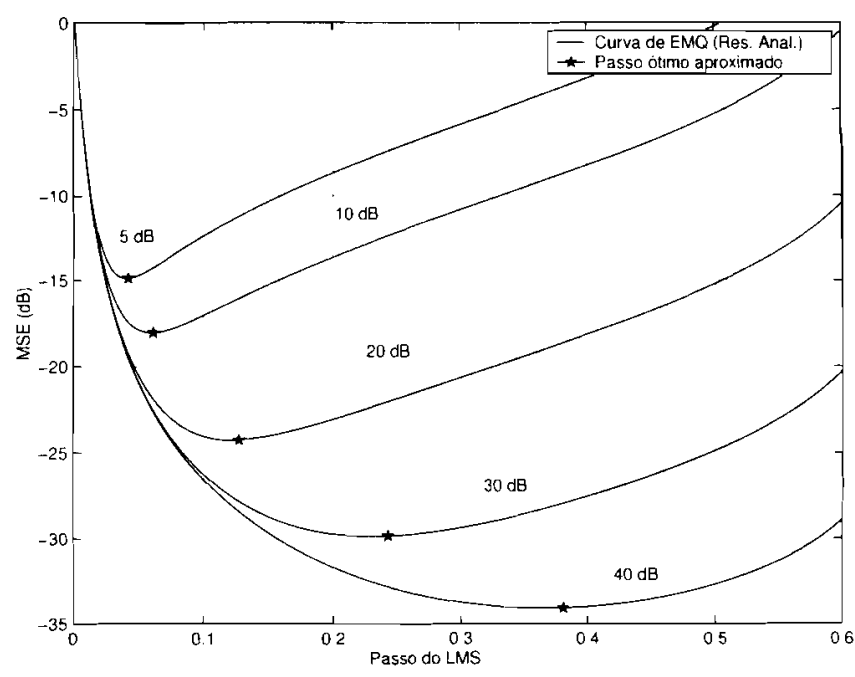

Figura 7. Curvas de EMQ em regime permanente obtidas analiticamente para o modelo de Jakes com $f_{D} T=0,001$. São destacados os valores de EMQ correspondentes aos valores de passo produzidos pelo procedimento proposto.

cientes são modelados por processos estacionários em sentido amplo com função de correlação conhecida.

$O$ EMQ em regime permanente foi obtido em termos da função de autocorrelação dos coeficientes da resposta ao impulso do canal de comunicação. Esses resultados foram particularizados para algumas formas de autocorrelação de grande interesse em sistemas de comunicação, tais como o modelo de Jakes e processos AR. Uma comparação entre resultados analíticos e de simulação computacional foi realizada, verificando-se um bom ajuste entre os mesmos, o que indica a validade das deduções desenvolvidas e, principalmente, das suposições feitas.

A otimização do passo no sentido de minimizar o EMQ em regime permanente também foi abordada neste trabalho. $\mathrm{O}$ cálculo exato do valor de passo ótimo foi obtido para os processos $\mathrm{AR}(1)$ e $\mathrm{AR}(2)$ com polos complexos conjugados. Além disso, foi proposto um procedimento para obter os passos ótimos para processos AR de ordens maiores, atendidas algumas restrições. Por fim, desenvolveu-se um procedimento para aproximar analiticamente o passo ótimo para modelos de Jakes. Resultados numéricos incluídos no trabalho mostram a validade da aproximação proposta.

Por fim, avaliou-se o desempenho do esquema de recepção MLSE-PSP que emprega o algoritmo de Viterbi para selecionar seqüências sobreviventes e o algoritmo LMS para obter estimativas condicionais da RI do canal. Ao contrário de outros trabalhos nessa linha de pesquisa, aqui modelouse o desvio Doppler máximo como uma variável aleatória e empregou-se o algoritmo LMS com passo otimizado, obtido pelo procedimento de aproximação proposto neste trabalho.

Os resultados de desempenho de um receptor MLSE-PSP com algoritmo LMS de passo otimizado através do procedimento proposto foram comparados com os obtidos para o mesmo tipo de receptor, porém com algoritmo LMS de passo fixo, cujo valor foi estabelecido no sentido de conferir boas propriedades de acompanhamento da RI do canal para a faixa de desvio Doppler máximo e RSR consideradas. Esses resul- 


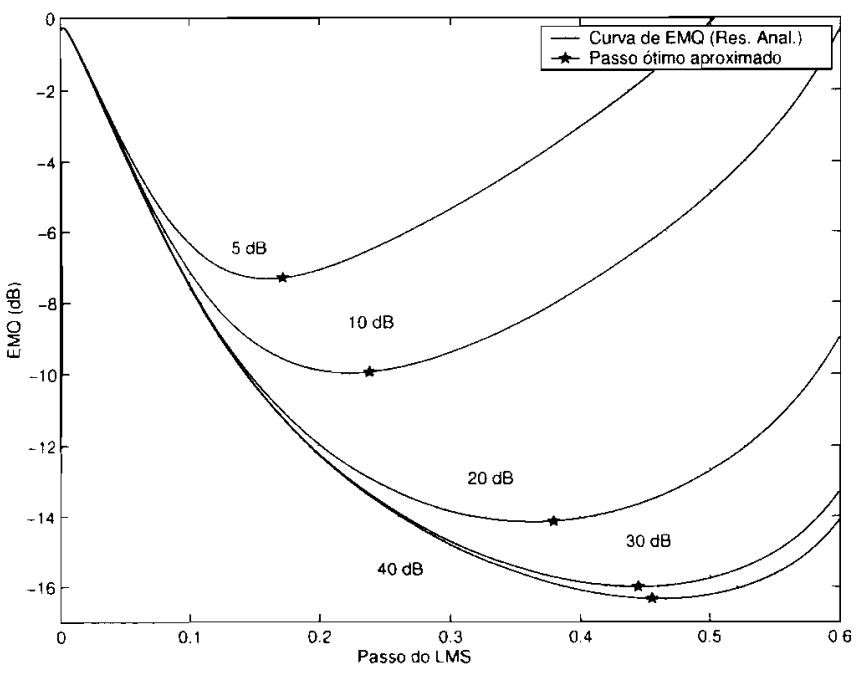

Figura 8. Curvas de EMQ em regime permanente obtidas analiticamente para o modelo de Jakes com $f_{D} T=0.01$. São destacados os valores de EMQ correspondentes aos valores de passo produzidos pelo procedimento proposto.

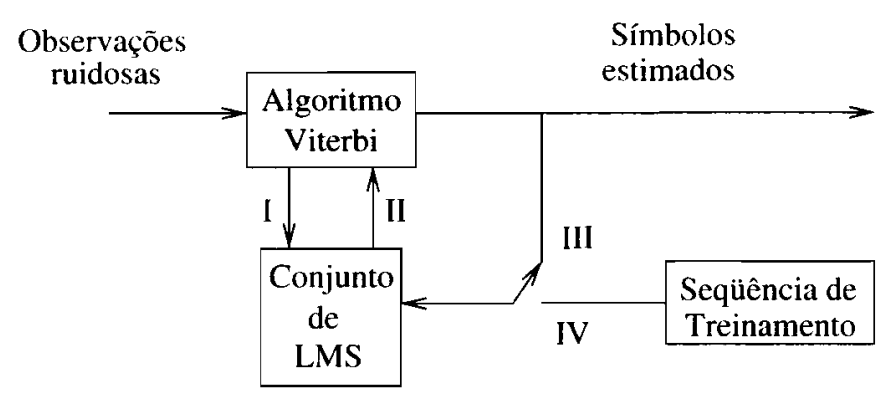

$$
\begin{aligned}
& \text { Legenda: I - Sequiências sobreviventes } \\
& \qquad \begin{array}{c}
\text { II - RI estimada } \\
\text { III - Modo de operação } \\
\text { IV - Modo de treinamento }
\end{array}
\end{aligned}
$$

Figura 9. Diagrama de blocos simplificado de um receptor MLSE-PSP.

tados mostraram que uma nítida vantagem de desempenho foi obtida com o procedimento de otimização do passo proposto.

Os resultados de simulação obtidos com o uso do passo otimizado são valiosos e interessantes, especialmente considerando o espectro de Jakes, que é amplamente empregado para modelar o efeito Doppler de canais de comunicação móvel, pois, neste caso, o passo ótimo fica parametrizado pela velocidade do equipamento de recepção, parâmetro de fácil obtenção, particularmente nos futuros sistemas de comunicações móveis que prevêem o uso de sistemas de posicionamento global.

Por fim, vale mencionar também que as deduções aqui apresentadas, particularmente as de EMQ em regime permanente, podem ter outros desdobramentos e aplicações. Um exemplo disso é o trabalho que os autores estão atualmente desenvolvendo no sentido de obter um procedimento para detecção de erros de equalização, que explora o EMQ em sua métrica de deteç̧ão. Este procedimento será objeto de publicações futuras.

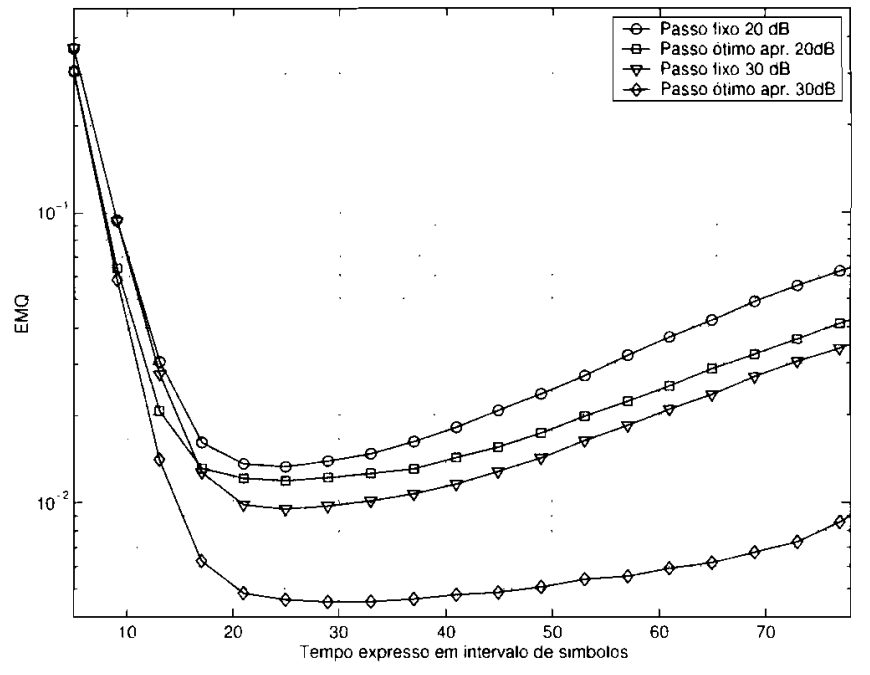

Figura 10. Curvas de aprendizagem do algoritmo LMS para os procedimentos de escolha do passo proposto e convencional, com RSR de 20 e $30 \mathrm{~dB}$.

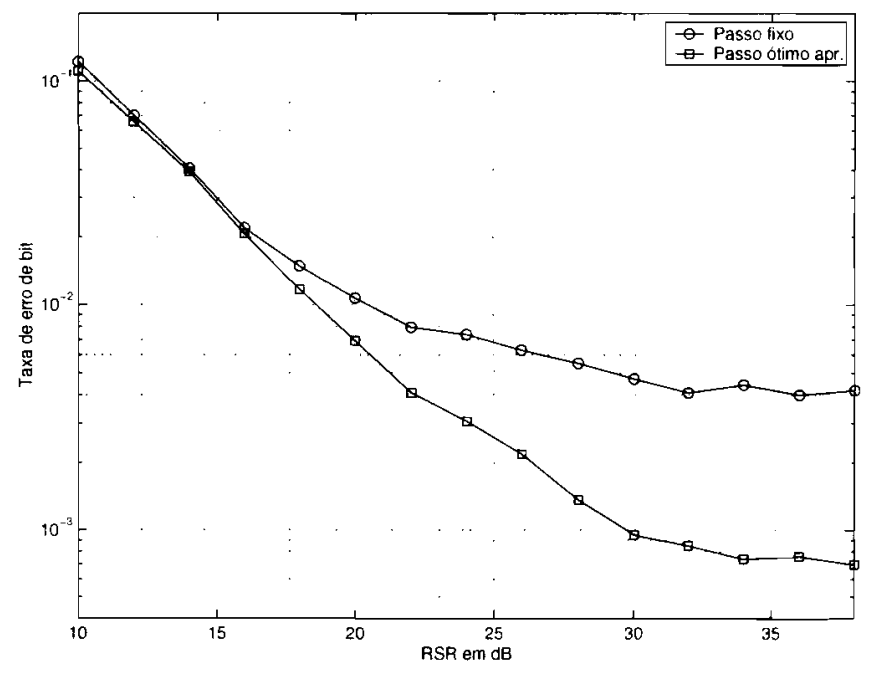

Figura 11. Taxa de erro de bit do receptor MLSE-PSP em função da RSR, para os esquemas de escolha de passo proposto e convencional.

\section{APÊNDICE}

\section{A. ERRO MÉDIO QUADRÁTICO}

Usando a Equação (11) na Equação (7), $\boldsymbol{K}(n+1)$ pode ser escrito como

$$
\boldsymbol{K}(n+1)=\boldsymbol{A}_{1}(n)+\boldsymbol{A}_{2}(n)+\boldsymbol{A}_{3}(n),
$$

sendo:

$$
\begin{aligned}
\boldsymbol{A}_{1}(n)= & \mathrm{E}\left[\boldsymbol { \epsilon } _ { p } ( n ) \left(\boldsymbol{\epsilon}_{p}^{*}(n)-\mu \epsilon^{*}(n) \boldsymbol{s}(n) \boldsymbol{s}^{*}(n)\right.\right. \\
& \left.\left.-\mu v(n) \boldsymbol{s}^{*}(n)\right)\right] \\
\boldsymbol{A}_{2}(n)= & -\mu \mathrm{E}\left[\boldsymbol { s } ( n ) \boldsymbol { s } ^ { * } ( n ) \boldsymbol { \epsilon } ( n ) \left(\boldsymbol{\epsilon}_{p}^{*}(n)\right.\right. \\
& \left.\left.-\mu \boldsymbol{\epsilon}^{*}(n) \boldsymbol{s}(n) \boldsymbol{s}^{*}(n)-\mu v(n) \boldsymbol{s}^{*}(n)\right)\right], \\
\boldsymbol{A}_{3}(n)= & -\mu \mathrm{E}\left[\boldsymbol { s } ( n ) v ^ { * } ( n ) \left(\epsilon_{p}^{*}(n)\right.\right. \\
& \left.\left.-\mu \boldsymbol{\epsilon}^{*}(n) \boldsymbol{s}(n) \boldsymbol{s}^{*}(n)-\mu v(n) \boldsymbol{s}^{*}(n)\right)\right] .
\end{aligned}
$$


Manipulando $\boldsymbol{A}_{1}(n)$, obtém-se

$$
\begin{aligned}
\boldsymbol{A}_{1}(n)= & \mathrm{E}\left[\boldsymbol{\epsilon}_{p}(n) \boldsymbol{\epsilon}_{p}^{*}(n)\right]-\mu \mathrm{E}\left[\boldsymbol{\epsilon}_{p}(n) \boldsymbol{\epsilon}^{*}(n) \boldsymbol{s}(n) \boldsymbol{s}^{*}(n)\right] \\
& -\mu \mathrm{E}\left[\boldsymbol{\epsilon}_{p}(n) v(n) \boldsymbol{s}^{*}(n)\right] .
\end{aligned}
$$

Os processos $\{\boldsymbol{w}(\cdot)\}$ e $\{\boldsymbol{s}(\cdot)\}$ são claramente estatisticamente independentes, inclusive pela independência de ordem física desses processos. Além disso, conforme a Suposição S2. na condição de regime permanente a estimativa de $\{\boldsymbol{w}(\cdot)\}$ também é estatisticamente independente de $\{s(\cdot)\}$. Diante desses fatos é razoável aceitar que $\epsilon(n)$ e $s(n)$ são estatisticamente independentes e que $\epsilon_{p}(n)$ e $s(n)$ também o são. Além disso, usando $\mathrm{SI}$ obtém-se

$$
\boldsymbol{A}_{1}(n)=\boldsymbol{K}_{p}(n)-\mu \tilde{\boldsymbol{K}}_{p}(n) \boldsymbol{R}_{\boldsymbol{s}}
$$

na qual:

$$
\begin{aligned}
\boldsymbol{K}_{p}(n) & =\mathrm{E}\left[\boldsymbol{\epsilon}_{p}(n) \boldsymbol{\epsilon}_{p}^{*}(n)\right], \\
\tilde{\boldsymbol{K}}_{p}(n) & =\mathrm{E}\left[\boldsymbol{\epsilon}_{p}(n) \boldsymbol{\epsilon}^{*}(n)\right] \quad \mathrm{e} \\
\boldsymbol{R}_{\boldsymbol{s}} & =\mathrm{E}\left[\boldsymbol{s}(n) \boldsymbol{s}^{*}(n)\right] .
\end{aligned}
$$

De forma similar, pode ser mostrado que:

$$
\begin{aligned}
\boldsymbol{A}_{2}(n)= & \mu^{2} \mathrm{E}\left[\boldsymbol{s}(n) \boldsymbol{s}^{*}(n) \boldsymbol{\epsilon}(n) \boldsymbol{\epsilon}^{*}(n) \boldsymbol{s}(n) \boldsymbol{s}^{*}(n)\right] \\
& -\mu \boldsymbol{R}_{\boldsymbol{s}} \tilde{\boldsymbol{K}}_{p}^{*}(n)
\end{aligned}
$$

$\mathrm{e}$

$$
\boldsymbol{A}_{3}(n)=\mu^{2} \sigma_{v}^{2} \boldsymbol{R}_{\boldsymbol{s}}
$$

Substituindo as equações (39), (41) e (42) na Equação (36), e usando a definição de $D(\cdot)$, obtém-se

$$
\begin{aligned}
D(n+1)= & \operatorname{Tr}\left[\boldsymbol{K}_{p}(n)-\mu \sigma_{s}^{2}\left(\tilde{\boldsymbol{K}}_{p}(n)-\tilde{\boldsymbol{K}}_{p}^{*}(n)\right)\right] \\
& +\mu^{2} \operatorname{Tr}\left\{\mathrm { E } \left[\boldsymbol{s}(n) \boldsymbol{s}^{*}(n) \boldsymbol{\epsilon}(n) \boldsymbol{\epsilon}^{*}(n)\right.\right. \\
& \left.\left.\cdot \boldsymbol{s}(n) \boldsymbol{s}^{*}(n)\right]\right\}+\mu^{2} \sigma_{v}^{2} \sigma_{s}^{2} L .
\end{aligned}
$$

Considerando a suposição S3, a propriedade de linearidade do operador $\mathrm{E}[\cdot]$ e que, para matrizes $\boldsymbol{A}$ e $\boldsymbol{B}$ com dimensões adequadas, $\operatorname{Tr}[\boldsymbol{A} \boldsymbol{B}]=\operatorname{Tr}[\boldsymbol{B} \boldsymbol{A}]$, o segundo termo do lado direito da Equação (43) torna-se

$$
\mu^{2} \operatorname{Tr}\{\boldsymbol{\Lambda}(n) \boldsymbol{K}(n)\},
$$

na qual foi admitido que

$$
\boldsymbol{\Lambda}(n)=\mathrm{E}\left[\boldsymbol{s}(n) \boldsymbol{s}^{*}(n) \boldsymbol{s}(n) \boldsymbol{s}^{*}(n)\right] .
$$

Pode ser mostrado que os elementos dessa matriz, denotados por $\Lambda_{j, k}$, são dados por

$\Lambda_{j . k}=\mathrm{E}\left[s(n-j+1) s^{*}(n-k+1) \sum_{l=0}^{L-1}|s(n-l+1)|^{2}\right]$, ou ainda por .

$$
\begin{array}{r}
\Lambda_{j, k}=\mathrm{E}\left[s(n-j+1) s^{*}(n-k+1)|s(n-j+1)|^{2}\right]+ \\
\mathrm{E}\left[s(n-j+1) s^{*}(n-k+1)|s(n-k+1)|^{2}\right]+ \\
\mathrm{E}\left[s(n-j+1) s^{*}(n-k+1) \sum_{l \neq j . l \neq k}|s(n-l+1)|^{2}\right] .
\end{array}
$$

Para os esquemas de modulação MPSK aqui considerados (Suposição S2), verifica-se que $\boldsymbol{\Lambda}(n)=L \sigma^{4} \boldsymbol{I}$.

Considerando os resultados apresentados acima $D(n+1)$ reduz-se a

$$
\begin{aligned}
D(n+1)= & \operatorname{Tr}\left[\boldsymbol{K}_{p}(n)-\mu \sigma_{s}^{2}\left(\tilde{\boldsymbol{K}}_{p}(n)-\tilde{\boldsymbol{K}}_{p}^{*}(n)\right)\right] \\
& +\mu^{2} L \sigma_{s}^{4} D(n)+\mu^{2} \sigma_{v}^{2} \sigma_{s}^{2} L .
\end{aligned}
$$

Usando as equações (8) e (12), são obtidas as seguintes expressões para $\boldsymbol{K}_{p}(n)$ e $\tilde{\boldsymbol{K}}_{p}(n)$ :

$$
\begin{aligned}
\boldsymbol{K}_{p}(n)= & 2\left[\boldsymbol{R}_{\boldsymbol{w}}(0)-\boldsymbol{R}_{\boldsymbol{w}}(1)\right]+\boldsymbol{K}(n) \\
& +\mathrm{E}\left[[\boldsymbol{w}(n+1)-\boldsymbol{w}(n)] \boldsymbol{\epsilon}^{*}(n)\right] \\
& +\mathrm{E}\left[\boldsymbol{\epsilon}(n)\left[\boldsymbol{w}^{*}(n+1)-\boldsymbol{w}^{*}(n)\right]\right], \\
\tilde{\boldsymbol{K}}_{p}(n)= & \boldsymbol{K}(n)+\mathrm{E}\left[(\boldsymbol{w}(n+1)-\boldsymbol{w}(n)) \boldsymbol{\epsilon}^{*}(n)\right] .
\end{aligned}
$$

Como pode ser verificado a partir da Equações (46) e (47), para obter o EMQ é preciso computar a correlação cruzada entre os coeficientes da RI do canal e o vetor erro, ou entre as estimativas dos coeficientes da RI do canal e o vetor erro.

Considera-se inicialmente a seguinte correlação cruzada:

$$
\begin{gathered}
\mathrm{E}\left[\boldsymbol{w}(n+1) \hat{\boldsymbol{w}}^{*}(n-l)\right]=\mathrm{E}\left\{\boldsymbol { w } ( n + 1 ) \left[\hat{\boldsymbol{w}}^{*}(n-l-1)+\right.\right. \\
\left.\left.\mu e(n-l-1) \boldsymbol{s}^{*}(n-l-1)\right]\right\} .
\end{gathered}
$$

Usando a definição de $e(\cdot)$ e as suposições S2 e S3, a Equação (48) pode ser reescrita como

$$
\begin{array}{r}
\mathrm{E}\left[\boldsymbol{w}(n+1) \hat{\boldsymbol{w}}^{*}(n-l)\right]=\mu \sigma_{s}^{2} \boldsymbol{R}_{\boldsymbol{w}}(l+2)+ \\
\left(1-\mu \sigma_{s}^{2}\right) \mathrm{E}\left[\boldsymbol{w}(n+1) \hat{\boldsymbol{w}}^{*}(n-l-1)\right] .
\end{array}
$$

Escrevendo a Equação (49) para $l=0$, tem-se

$$
\begin{aligned}
& \mathrm{E}\left[\boldsymbol{w}(n+1) \hat{\boldsymbol{w}}^{*}(n)\right]=\mu \sigma_{s}^{2} \boldsymbol{R}_{\boldsymbol{w}}(2)+ \\
& \left(1-\mu \sigma_{s}^{2}\right) \mathrm{E}\left[\boldsymbol{w}(n+1) \hat{\boldsymbol{w}}^{*}(n-1)\right] .
\end{aligned}
$$

De acordo com a Equação (49) para $l=1$, tem-se

$$
\begin{gathered}
\mathrm{E}\left[\boldsymbol{w}(n+1) \hat{\boldsymbol{w}}^{*}(n-1)\right]=\mu \sigma_{s}^{2} \boldsymbol{R}_{\boldsymbol{w}}(3)+ \\
\left(1-\mu \sigma_{s}^{2}\right) \mathrm{E}\left[\boldsymbol{w}(n+1) \hat{\boldsymbol{w}}^{*}(n-2)\right],
\end{gathered}
$$

substituindo a Equação (51) na Equação (50) chega-se a

$$
\begin{gathered}
\mathrm{E}\left[\boldsymbol{w}(n+1) \hat{\boldsymbol{w}}^{*}(n)\right]=\mu \sigma_{s}^{2} \boldsymbol{R}_{\boldsymbol{w}}(2)+\mu \sigma_{s}^{2}\left(1-\mu \sigma_{s}^{2}\right) \\
\cdot \boldsymbol{R}_{\boldsymbol{w}}(3)+\left(1-\mu \sigma_{s}^{2}\right)^{2} \mathrm{E}\left[\boldsymbol{w}(n+1) \hat{\boldsymbol{w}}^{*}(n-2)\right]
\end{gathered}
$$

Usando a Equação (49) para $l=2$ na equação acima, repetindo esse procedimento recorrentemente até que $l=$ $n-1$ e utilizando o fato de que $\hat{\boldsymbol{w}}(0)=0$, chega-se ao seguinte resultado:

$\mathrm{E}\left[\boldsymbol{w}(n+1) \hat{\boldsymbol{w}}^{*}(n)\right]=\sum_{l=0}^{n-1}\left(1-\mu \sigma_{s}^{2}\right)^{l} \mu \sigma_{s}^{2} \boldsymbol{R}_{\boldsymbol{w}}(l+2)$.

De forma similar, pode-se mostrar que

$$
\begin{aligned}
\mathrm{E}\left[\boldsymbol{w}(n) \hat{\boldsymbol{w}}^{*}(n-l)\right]= & \left(1-\mu \sigma_{s}^{2}\right) \mathrm{E}\left[\boldsymbol{w}(n) \hat{\boldsymbol{w}}^{*}(n-l-1)\right] \\
& +\mu \sigma_{s}^{2} \boldsymbol{R}_{w}(l+1) .
\end{aligned}
$$


Iniciando com $l=0$ e usando recursivamente a Equação (54) até que $l=n-1$, e considerando que $\hat{w}(0)=0$, chegase a

$$
\mathrm{E}\left[\boldsymbol{w}(n) \hat{\boldsymbol{w}}^{*}(n)\right]=\sum_{l=0}^{n-1}\left(1-\mu \sigma_{s}^{2}\right)^{l} \mu \sigma_{s}^{2} \boldsymbol{R}_{\boldsymbol{w}}(l+1)
$$

Das equações (53), (55) e (8), obtém-se

$$
\begin{array}{r}
\mathrm{E}\left\{[\boldsymbol{w}(n+1)-\boldsymbol{w}(n)] \boldsymbol{\epsilon}^{*}(n)\right\}=\boldsymbol{R}_{\boldsymbol{w}}(1)-\boldsymbol{R}_{\boldsymbol{w}}(0)+ \\
\sum_{l=0}^{n-1}\left(1-\mu \sigma_{s}^{2}\right)^{l} \mu \sigma_{s}^{2}\left[\boldsymbol{R}_{\boldsymbol{w}}(l+1)-\boldsymbol{R}_{\boldsymbol{w}}(l+2)\right]
\end{array}
$$

Usando a Equação (56) nas equações (47) e o resultado na Equação (46). chega-se finalmente a

$$
\begin{aligned}
& D(n+1)=\left(1-2 \mu \sigma_{s}^{2}+\mu^{2} L \sigma_{s}^{4}\right) D(n)+\mu^{2} \sigma_{v}^{2} \sigma_{s}^{2} L+ \\
& \left.2 \mu \sigma_{s}^{2} \sum_{l=-1}^{n-1}\left(1-\mu \sigma_{s}^{2}\right)^{l+1} \operatorname{Tr}\left[\boldsymbol{R}_{\boldsymbol{w}}(l+1)-\boldsymbol{R}_{\boldsymbol{w}}(l+2)\right]\right]
\end{aligned}
$$

\section{AGRADECIMENTOS}

Os autores gostariam de expressar os agradecimentos ao $\mathrm{CNPq}$ pelo apoio financeiro e aos revisores anônimos, cujas sugestões contribuíram sobremaneira para melhorar o trabalho.

\section{REFERÊNCIAS}

[1] S. Haykin. Adaptive Filter Theory. Prentice Hall, 1991.

[2] B. Farhang-Boroujeny and H. Gazor. "Performance of LMSBased Adaptive Filters in Tracking a Time-Varying Plant". IEEE Transactions on Signal Processing, vol. 44, no. 11, pp. 2868-2871, November 1996.

[3] E. Eweda. "Comparation of RLS, LMS and Sign Algorithms for Tracking Randomly Time-Varying Channels". IEEE Transactions on Signal Processing, vol. 42, no. 11, pp. 29372944, November 1994.

[4] N. R. Yousef and A. H. Sayed. "A Unified Approach to the Steady-State and Tracking Analyses of Adaptive Filters". IEEE Transactions on Signal Processing, vol. 49, no. 2, pp. 314-324, February 2001.

[5] P. S. R. Diniz. Adaptive Filtering Algorithms and Practical Implementation. Kluwer Academic Publishers, 1997.

[6] J. D. Parsons. The Mobile Radio Propagation Channel. John Wiley, 1992.

[7] J. G. Proakis. Digital Communications. McGraw-Hill, 1995.

[8] A. Papoulis. Probability, Random Variables, and Stochastic Processes. McGraw-Hill, 1991.

[9] M. E. Rollins and S. J. Simmons. "Simplified Per-Survivor Kalman Processing in Fast Frequency-Selective Fading Channels". IEEE Transactions on Communications, vol. 45, no. 5 , pp. 544-553, May 1997.

[10] Q. Dai and E. Shwedyk. "Detection of Bandlimited Signals Over Frequency Selective Rayleigh Fading Channels". IEEE Transactions on Communications, vol. 42, no. 2/3/4, pp. 941950, February 1994.

[11] J. F. Galdino and E. L. Pinto. "A Simulation Study of Adaptive Filtering Applied to MLSE-PSP Receivers". In IEEE Military Communications Conference (MILCOM), 1998.
[12] Y. Zhang, M. Fitz and S. B. Gelfand. "Soft Output Demodulation on Frequency-Selective Rayleigh Fading Channels Using AR Channel Models". In IEEE Global Telecommunications Conference (GLOBECOM), November 1997.

[13] H. P. William, B. P. Flannery, S. A. Teukolsky and W. T. Vetterling. Numerical Recipes in C: The Art of Scientific Computing. Cambridge University Press, 1993.

[14] G. D. J. Forney. "Maximum-Likelihood Sequence Estimation of Digital Sequences in the Presence of Intersymbol Interference". IEEE Transactions on Information Theory, vol. 18, no. 3, pp. 363-378, May 1972.

[15] K. M. Chugg and A. Polydoros. "MLSE for Unknown Channel - Part 1: Optimality Considerations". IEEE Transactions on Communications, vol. 44, no. 7, pp. 836-846, July 1996.

[16] K. M. Chugg and A. Polydoros. "MLSE for Unknown Channel - Part II: Tracking Performance". IEEE Transactions on Communications, vol. 44, no. 8, pp. 949-958, August 1996.

[17] J. F. Galdino and E. L. Pinto. "A New MLSE-PSP Scheme Over Fast Frequency-Selective Fading Channels". In IEEE International Symposium on Information Theory and its Applications (ISITA), 1998.

[18] G. D. J. Forney. "The Viterbi Algorithm". Proceedings of the IEEE, vol. 61, no. 3, pp. 268-278, March 1973.

[19] R. Raheli, A. Polydoros and C. Tzou. "Per-Survivor Processing: A General Approach MLSE in Uncertain Environments". IEEE Transactions on Communications, vol. 43, no. 2/3/4, pp. 354-364, February/March/April 1995.

Juraci Ferreira Galdino nasceu em Malta, Paraiba, em 1967. Formou-se em Engenharia Elétrica pela Universidade Federal da Paraiba em 1991. Formou-se Oficial Engenheiro Militar do Exército Brasileiro pelo Instituto Militar de Engenharia em 1992. Recebeu o título de mestre em Engenharia Elétrica pelo Instituto Militar de Engenharia em 1998 e o título de Doutor em Ciências pela Universidade Federal de Campina Grande em Dezembro de 2002. Desde Janeiro de 2003 é professor do Instituto Militar de Engenharia. Suas pesquisas concentram-se principalmente em wavelets, filtragem adaptativa e comunicações móveis. $\hat{E}$ autor de diversos trabalhos publicados em anais de congressos de sociedades científicas nacionais e internacionais e um dos autores do livro Communications, Information and Network Security, pela Kluwer Academic Publishers. Juraci Ferreira Galdino é membro da Sociedade Brasileira de Telecomunicações (SBrT) e do Instituto de Engenheiros Eletricistas e Eletrônicos (IEEE).

Ernesto Leite Pinto graduado em Engenharia Elétrica pela Universidade Federal da Paraíba, em 1983, tem mestrado e doutorado na área de sistemas de comunicações pela PUC/Rio, concluídos em 1986 e 1998, respectivamente. Suas principais áreas de pesquisa são: avaliação de desempenho de sistemas de transmissão digital e processamento digital de sinais aplicado a sistemas de comunicações digitais. É professor adjunto IV do Departamento de Engenharia Elétrica (DEE) do IME, onde trabalha desde 1987 e orientou diversas dissertações de mestrado. Exerce também a função de chefe da área de concentração de Telecomunicações do programa de mestrado do DEE/IME. Trabalhou recentemente como professor visitante e participa do programa de pós-graduação do Departamento de Engenharia Elétrica da Universidade Federal da Paraiba, onde co-orientou uma tese e alualmente co-orienta um segundo trabalho de doutorado. É autor de diversos trabalhos publicados em anais de congressos e revistas de sociedades científicas nacionais e internacionais. Participou de várias bancas de avaliação de dissertações de mestrado e teses de doutorado em diversas instituições importantes do país. Trabalhou junto aos departamentos de treinamento da Eembratel e da Telerj, como autor 
de texıos didáticos e professor, na área Comunicações Digitais. É sócio e fez parte do Conselho Deliberativo da Sociedade Brasileira de Telecomunicações.

Marcelo Sampaio de Alencar nasceu em Serrita, Pernambuco, em 1957. Formou-se em Engenharia Elétrica pela Universidade Federal de Pernambuco, em 1980, recebeu o título de mestre em Engenharia Elétrica pela Universidade Federal da Paraíba (UFPB). em 1988 e o de Ph.D. em Engenharia Elétrica pela University of Waterloo. Canada, em 1993. Durante o período de 1982 a 1984 trabalhou na Faculdade de Engenharia da Universidade para o Desenvolvimento do Estado de Santa Catarina, onde foi Membro Titular do Conselho Universitário e Vice-Presidente da Associação dos Professores. Atualmente trabalha no Departamento de Engenharia Elétrica da Universidade Federal de Campina Grande (UFCG), onde exerce o cargo de Professor Titular. Exerceu os cargos de Vice-Coordenador do Curso de Engenharia Elétrica, Assessor de Extensão do Centro de Ciências e Tecnologia, Presidente da Comissão de Extensão do Centro de Ciências e Tecnologia da UFPB e foi Membro nato do Comitê Assessor de Extensão da Universidade Federal da Paraíba. Atualmente exerce a Coordenação da Área de Comunicações do Departamento, com cadastro no CNPq. Professor do Programa de
Pós-graduação da Universidade Federal de Pernambuco (UFPE) e foi Professor do Programa de Pós-graduação Lato Sensu da Universidade Federal do Maranhão (UFMA). Foi Professor Visitante no Departamento de Engenharia Elétrica e de Computação. Universidade de Toronto, entre julho e agosto de 1997. Revisor da revista IEEE Transactions on Communications, da Revista Brasileira de Telecomunicaçoes, da Sociedade Brasileira de Telecomunicações, da revista IEEE Transactions on Vehicular Technology, da revista Wireless Personal Communications, da Kluwer Academic Publishers. Membro da Comissão Brasileira de Comunicações 2 da Anatel. Áreas de interesse em pesquisa: Processamento de Sinais, Comunicações Ópticas, Comunicações Móveis, Teoria da Comunicação e Informação, Efeitos Biológicos da Radiação, áreas em que tem mais de 100 artigos publicados. Tem sua biografia incluida nas publicações Who"s Who in the World, Who`s Who in Science and Engineering. Marcelo Sampaio de Alencar é autor dos livros Telefonia Digital (Quarta Edição) e Sistemas de Comunicações, pela Editora Érica Ltda, autor do livro Princípios de Comunicações, pela Editora Universitária, UFPB, um dos autores do livro Communications, Information and Network Security, pela Kluwer Academic Publishers, e articulista do Jornal do Commércio On Line, de Recife, assinando a coluna Difusão. de divulgação científica, desde abril de 2000. 